\title{
1 Social coercion of larval development in an ant
}

2 Irene Villalta ${ }^{a b^{*}}$, Sévrine Antille ${ }^{c}$, Fernando Amor $^{a}$, Xim Cerdá $^{a}$ and Raphaël Boulay ${ }^{b}$

3

4 a Estación Biológica de Doñana, Consejo Superior de Investigaciones Cientificas, Seville,

5 Spain.

6 b Institut de Recherche sur la Biologie de l'Insecte, Université François Rabelais, Tours,

7 France.

$8 \quad{ }^{\mathrm{c}}$ Department of Ecology and Evolution, University of Lausanne, Switzerland.

9

10 *Author Correspondence: irenevillaltaalonso@gmail.com 
16 Keywords: aggressions, ant, Aphaenogaster senilis, caste productions, cuticular

17 hydrocarbon, social policing

18 


\section{Introduction}

Colonies of eusocial insects are characterized by elevated cooperation and division of labor whereby a large number of workers forego their own direct reproduction to participate in domestic tasks such as collecting food and rearing the brood (Wilson 1971; Heinze et al. 1994). Yet, the apparent harmony of the colony is often punctuated of conflicts over who will reproduce and who will not (Chapuisat and Keller 1999). In some primitive ant species, for example, all young females are born with a spermatheca and could potentially mate. Why do then most individuals commit themselves to become helpers? It was shown that only behaviorally dominant females reproduce whereas challengers are coerced by the group to remain steriles (Peeters and Higashi 1989; Peeters et al. 1992; Ito 1993; Monnin and Peeters 1999; Tay and Crozier 2000; Monnin and Ratnieks 2001). In more evolved species, diploid brood sexualization gives rise to morphologically distinct worker and queen casts. This limits reproductive conflicts among adults since the worker has lost the capacity to mate. However, conflicts remain among larvae which are bipotent and can develop into either casts (BourkeandRatnieks 1999). Hence, any diploid larva may expect a higher direct fitness by developing into a queen rather than into a worker. Adults, in contrast, should prefer a large amount of colony resources being allocated to the production of workers to guarantee colony survival and growth.

Conflicts over larval caste fate may be particularly exacerbated in species that disperse through colony fission (Pamilo 1991; Boulay et al. 2007). During fission, new colonies are formed when a young queen abandons the mother colony with a group of workers (Cronin et al. 2013). Thus, queens are protected by workers throughout their life and, from the adult perspective, the development of a very low proportion of diploid larvae into queens is sufficient to ensure colony reproduction. This, in turn, enhances competition between larvae to become a queen suggesting a complex social regulation of queen production may evolve (Bourke and Ratnieks 1999). For workers, one way of regulating the production of new queens is by controlling larval food intake, thus limiting larval growth 
(Bonavita-Cougourdan and Passera 1978). This is supported by the observation that honeybee queen larvae are provisioned with specific proteins that are contained in the royal jelly (Kamakura 2011; Wolschin et al. 2011) and that queen-destined ant larvae receive a protein-enriched diet compared to worker-destined larvae (Smith et al. 2008; Smith and Suarez 2010; Caut et al. 2013). In addition of controlling food, the adults may control larvae sexualizaton by physically aggressing cheating larvae as in Myrmica species and Harpegnathos saltator (Brian 1973; Penick and Liebig 2012).

The role of the queen in the policing of larvae is controversial (Vargo and Passera 1991). However, the implication of her pheromones in the regulation of sexual production is known in several species of ants and bees. These chemicals can directly inhibit larvae sexualization (Vargo and Passera 1991; Cnaani et al. 1997; Bourke and Ratnieks 1999) or indirectly modify worker behavior, provoking the policing of undesired queen larvae (Boulay et al. 2007). Finally, the queen may use chemical marks from her Dufour (or other) gland to mark challengers and encourage punishment by workers (Gilley 2001; Monnin et al. 2002; van Zweden and d'Ettorre 2010).

In the present study, we analyzed the social regulation of queen production in the colonies of the ant Aphaenogaster senilis, a common species that disperses by colony fission. While diploid larvae are bipotent until the second larval instar, in natural conditions, most larvae develop into workers (Boulay et al. 2009). Young queens are produced in very small numbers and only in rare occasions, when the colony is large enough to permit fission or if the fertile queen dies (Boulay et al. 2007; Boulay et al. 2009). In queenless condition, the production of new queens increases non-linearly with the number of bipotent larvae and never exceeds 6-7 individuals (Ruel et al. 2012; Villalta et al. 2015). To explain this, it has been hypothesized that the first queen-destined larvae could signal their presence in order to enforce younger larvae development into workers. We conducted bioassays to determine if workers are able to police undesired queen larvae and if this depended on the perception of queen pheromones. Then, we tested if queen-destined larvae had a negative effect on younger larvae sexualization. Finally, we performed chemical analyses to compare the 
cuticular hydrocarbon (HCs) profiles of queen- and worker-destined larvae in order to determine if these compounds could serve to signal larval caste fate. Many authors point at cuticular HCs as the main fertility signal in adults (Liebig et al. 2000; Cuvillier-Hot et al. 2001; Endler et al. 2004; Le Conte and Hefetz 2008) but their role in the recognition of larval caste fate is still unknown.

\section{MATERIALS AND METHODS}

Model system, colony collection and maintenance in the laboratory

Aphaenogaster senilis is a monandrous and monogynous species that is distributed over most of the Iberian Peninsula. Source colonies were collected in the Doñana National Park, southwestern Spain, between June 2007 and September 2012. In the laboratory, they were housed in artificial nests composed of an open plastic box $(28 \times 18 \times 11 \mathrm{~cm})$, the internal wall of which was lined with Fluon to prevent escapes. The ants were allowed to shelter in five 20 $\mathrm{cm}$ long test tubes filled in their first third with water retained by a cotton plug. They were maintained under controlled conditions $\left(27^{\circ} \mathrm{C}, 50 \%\right.$ humidity $)$ and fed three times a week with sliced mealworms, Tenebrio molitor.

\section{Experiment 1: Worker and queen control on larvae sexualization.}

In order to obtain as many queen larvae as required to conduct the experiment, we first created two production groups from each of 25 collected colonies. Each production group was composed of 200 workers and $201^{\text {st }}$ instar larvae. The production groups were checked daily and as soon as a queen-destined $3^{\text {rd }}$ instar larva was detected she was immediately introduced together with a worker-destined $3^{\text {rd }}$ instar larva in an observation group of 50 workers from their respective source colony. The observation groups were placed in Petri dishes ( $9 \mathrm{~cm}$ diameter) in one of the following resident conditions: 1 ) the source colony queen was present and free to move in the dish (queenright, $Q R, n=15$ ); 2) the source colony queen was present in the dish but she was encaged in a $2 \mathrm{~mL}$ tube, the cap of which had been replaced by a wire mesh allowing chemical volatile exchange with the workers 
(Qen, $n=12$ ); 3) the workers were in contact with the queen in the source colony until the

101

102

103

104

105

106

107

108

109

110

111

112

113

114

115

116

117 beginning of the experiment but not during the observation period (queenless, $Q L, n=15$ ); 4) the workers were already queenless for two weeks at the beginning of the observation period (QL2w, $n=9$ ). Humidity was maintained in the Petri dishes by a moisten cotton plug.

Behavioral observations started 30 minutes after larval introduction and lasted 30 minutes. Every minute, we recorded the number of ants that interacted with each larva and, among these interactions, the number of aggressive behaviors (bites and threats, i.e. opening the mandibles with the gaster bent below the thorax). We then monitored both larvae survival during 5 days. At the end of each experiment, all the adult ants, including the queen, were returned their respective source colony. Each of the 25 source colonies was used successively in one to four experiment corresponding to different resident conditions and with at least a month apart.

\section{Experiment 2: Effect of already determined larvae on younger larvae sexualization.}

As previously, we started by creating two production groups of 200 workers and $201^{\text {st }}$ instar larvae from each of 20 recently collected source colonies. Larval development into worker or queen was monitored daily during three weeks. Once the first $3^{\text {rd }}$ instar queen-destined larva was detected in the production group, we immediately created two experimental groups from the same source colonies, both composed of 200 workers and $201^{\text {st }}$ instar larvae. One experimental group received the $3^{\text {rd }}$ instar queen-destined larva while the other group received a $3^{\text {rd }}$ instar worker-destined larva from either production groups from the same source colony. We then continued supplying both experimental groups with the same numbers of queen-destined or worker-destined $3^{\text {rd }}$ instar larvae as they appeared in the production groups during the following 7 days. The total number of supplied larvae varied from 1 to 6 depending on the availability of queen-destined larvae in the production groups (the availability in worker larvae was not limiting). On the $8^{\text {th }}$ day, all the $3^{\text {rd }}$ instar supplied larvae were removed (some of them had already reached the pupal stage) and we then 
monitored the development of the $1^{\text {st }}$ instar larvae during the following 6 weeks at each experimental group.

Chemical analyses

Twelve worker-destined and 12 queen-destined larvae were selected from 12 different queenless colonies. The larvae were first photographed using a stereomicroscope equipped of digital camera. We used imageJ free software to measure the length (a) and width (c) of each larva. Both measurements were considered as the two semi axis of a prolate spheroid, the surface of which was calculated as:

$S=2 \pi a^{2}(1+a$ cle $\arcsin (e))$ with $e=\sqrt{ }\left(1-a^{2} / c^{2}\right)($ Beyer 1987)

The larvae were killed and were immersed in $100 \mu \mathrm{L}$ of hexane during one hour to extract their cuticular HCs. We then removed the corpses and evaporated the samples under a nitrogen flow. The extracts were stored at $4^{\circ} \mathrm{C}$ until their injection into a gas chromatograph (GC 2010 Shimadzu) equipped with a Flame Ionization Detector. The temperature program ran from $130^{\circ} \mathrm{C}$ to $240^{\circ} \mathrm{C}$ at $15^{\circ} \mathrm{C} \mathrm{min}^{-1}$, and then from $240^{\circ} \mathrm{C}$ to $300^{\circ} \mathrm{C}$ at $3^{\circ} \mathrm{C} \mathrm{min}^{-1}$. Each sample received $20 \mathrm{ng}$ of $\mathrm{C} 20$ as an internal standard. Once all the samples were run in GCFID, they were pooled by caste and injected into a Perkin Elmer TurboMass GC mass spectrometer with similar chromatographic conditions for peaks identification.

\section{Data analysis}

All statistical analyses were performed using the R software v. 2.14.1 (R Core Team 2012).

The behavioral results of the first experiment (the average number of contacts and aggressions between the workers and the introduced worker-destined or queen-destined $3^{\text {rd }}$ instar larvae) were analyzed using linear mixed-effect models (Lmer; Ime4 package) where the resident condition, the caste of the introduced larva and the interaction were fixed effects while the colony of origin was a random effect. Larval mortality rate after 5 days was compared between treatments by fitting a generalized linear model with the binomial family. Although this kind of model better fits to binary data such as death vs survival, they do not 
provide accurate estimation of the main effects. Only the differences between levels are given in the result section.

For experiment 2, a linear mixed-effect model was fitted to test the effect of the number and caste of larvae added during the first week and the interaction between them on the total production of female pupae during the remaining six weeks of experiment. The colony of origin was included in the model as a random effect. A similar model was fitted using the proportion of queens among the produced female pupae as a response variable, while using the same fixed and random effects. In addition, we tested for the effect of the colony of origin by comparing both the total numbers of produced females and the proportion of queens in the groups receiving worker-destined and queen-destined $3^{\text {rd }}$ larvae for the same source colony by means of the Pearson correlation test.

The amount of each $\mathrm{HC}$ was calculated based on the peak area compared with the internal standard and reported on the body surface. The Wilcoxon test was used to compare each compounds quantities in worker-destined and queen-destined larvae. The HolmBonferroni correction was used to control for family-wise multiple comparisons. Given that 10 null hypotheses were tested, the lowest $\alpha$ was set to 0.005 instead of 0.05 .

\section{RESULTS}

\section{Experiment 1: Worker and queen control on larval sexualization.}

Worker policing towards undesired queen-destined larvae was contingent on the presence of the queen. The average number of contacts between the workers and the introduced larvae was a function of the resident condition (Fig. 1a; Imer: $F_{3,91}=31.40, P<0.0001$ ), the caste of the introduced larva $\left(F_{1,78}=38.10, P<0.0001\right)$ and their interaction $\left(F_{3,78}=3.84, P=0.012\right)$. Hence, there were overall more worker contacts directed towards queen-destined larvae than to worker-destined larvae in the QR, Qen and QL groups but not in the QL2w groups. A similar pattern occurred for aggressive interactions (Fig. $1 \mathrm{~b}$; Imer: resident condition: $F_{3,87}=$ 2.41, $P=0.072$; intruder caste: $F_{1,64}=25.01, P<0.0001$; interaction: $F_{3,64}=2.99, P=0.037$ ). Although QR, Qen and QL workers behaved more aggressively towards queen-destined 
larvae than to worker-destined larvae, there was no significant different for QL2w ants(Fig. 1b). Contacts and aggressions between QL2w workers and larvae were significantly lower than in other condition irrespective of larval caste fate (Fig.1a,b).

The relatively high aggression level observed in the QR group towards queendestined larvae led into a high level of mortality compared to worker-destined larvae (Fig. 2; glmer: $z=3.513, P=0.0004)$. However, in the other resident conditions including the Qen and QL conditions, there was no such significant difference between the mortality rate of worker and queen larvae. QL2w queen-destined larvae displayed similar survival rates to Qen and QL conditions (Fig.2).

\section{Experiment 2: Effect of already determined larvae on younger larvae sexualization.}

The results of the second experiment provided no evidence of a negative impact of the presence of queen-destined larvae on young larvae sexualization. Over the seven weeks of experiment, the number of $1^{\text {st }}$ instar larvae that developed into worker or queen pupae was neither related to the caste nor to the number of the $3^{\text {rd }}$ instar larvae that were provided during the first week (Fig. 3a; Imer: Caste: $F_{1,18}=0.04, P=0.85$; Number: $F_{1,18}=0.003, P=$ 0.96). The interaction between the caste and the number of provided larvae was not significant either (Imer: Caste $\times$ Number: $F_{1,18}=0.05, P=0.83$ ). Only 7 male pupae were produced over the whole experiment. The proportion of queen pupae among the females decreased significantly with the number of $3^{\text {rd }}$ instar larvae supplied (Fig. 3b; Imer: Number: $\left.\mathrm{F}_{1,18}=25.92, \mathrm{P}>0.0001\right)$ but was not significantly associated with their caste (Imer: Caste: $\left.F_{1,18}=4.38, P=0.051\right)$. The Caste $x$ Number interaction did not affect significantly the proportion of queens among the female pupae (Imer: Caste $x$ Number: $F_{1,18}=1.79, P=$ $0.20)$.

The identity of the mother colony accounted for an important partition of the total variance in the number of diploid pupae and in the proportion of queens among the females ( $70.2 \%$ and $60 \%$, respectively). This was also evidenced by the significant correlation between both the number of females and the proportion of queens that were produced in 
both experimental groups created from each mother colony (Fig. S1; Pearson correlation: $\mathrm{t}_{18}$ $=4.25, \mathrm{P}=0.0004$ and $\mathrm{t}_{18}=5.95, \mathrm{P}<0.0001$, respectively).

Cuticular hydrocarbon analyses.

209

210

211

212

213

214

215

216

217

218

219

220

221

222

223

224

225

Both worker and queen larvae were relatively depauperate in HCs. GC-MS analysis revealed only 10 peaks that corresponded to $11 \mathrm{HCs}$, ranging from 25 to 30 carbon chain-length (Table 1). Methyl-branched alkanes represented on average $37 \pm 4 \%$ and $29 \pm 5 \%$ of the total amount of HCs in queen and worker larvae, respectively. The remaining were linear alkanes. Dimethyl alkanes were completely absent. On average, queen larvae contained 1.7 times more HCs than worker larvae $\left(21.7 \pm 1.4\right.$ ng.larva $^{-1}$ vs $12.6 \pm 0.8$ ng.larva ${ }^{-1}$, respectively; Wilcoxon test: ). However, when reported to larvae cuticular surface, the amount of $\mathrm{HCs}$ per $\mathrm{mm}^{2}$ was not significantly different between queen and worker larvae (5.58 ng. $\mathrm{mm}^{-2}$ vs 6.59 ng. $\mathrm{mm}^{-2}$; Wilcoxon test: $\mathrm{W}=57, \mathrm{P}=0.41$ ). After the Holm-Bonferroni correction applied to control for family-wise multiple comparisons, no compound had different amounts per unit of surface between castes (Table1).

\section{DISCUSSION}

As it is probably the case in many species of social hymenoptera, young larvae of $A$. senilis are bipotent and can develop into workers or queens depending on environmental conditions. Theory predicts that an individual larva may expect a greater direct fitness by developing into queen (Bourke and Ratnieks 1999), so why do most larvae forgo reproduction to commit themselves to become helpers? Previous results have shown that workers may coerce larval development by controlling food quality and quantity (Ichinose et al. 2009). The present study shows that, in addition, workers may police cheating larvae and that this behavior depends on the perception of queen pheromones. However, in contrast to what was previously hypothesized, queen-destined larvae do not inhibit younger larvae sexualization. Finally, chemical analyses did not allow identifying a queen-specific HC profile at the larval stage. 
233 in insect societies (Wenseleers et al. 2004). Depending on the species, worker aggressions

234 were shown to be directed toward individuals that could potentially challenge the

235 reproductive monopoly of the queen (Kikuta and Tsuji 1999; Monnin and Ratnieks 2001;

236 Ruel et al. 2013a). The results of experiment 1 show that worker policing also serves as a

237 mechanism controlling larval development into worker. When a queen was present and free

238 to move in the experimental Petri dish, the adult workers specifically aggressed the queen

239 larva but not the worker larva. This led to the death of most of the queen larvae in less than 5

240 days while the worker larvae survived. In contrast, when the adult workers had been

241 queenless for two weeks before the beginning of the experiment (QL2w condition), they less

242 interacted with and aggressed the larvae. As a result, both larvae survived well during 5

243 days. Queen removal or isolation in a cage ( $Q L$ and Qen conditions, respectively) had no

244 short-term effect on workers' behavior: they were still highly aggressive towards queen

245 larvae during the first hour. However, after 5 days, queen larvae mortality was low in both

246 experimental conditions and not significantly different from worker larvae mortality. Although

247 3rd instar larvae did not experience aggression from workers in the QL2w condition, their

248 mortality rates were similar to those of Qen and QL $3^{\text {rd }}$ instar larvae irrespective of their

249 caste. A first possible explanation for this result is that policing is contingent of the perception

250 of queen pheromones, the effect of which lasts even after the queen has disappeared (). A

251 second possible non exclusive explanation is that the queen actively participates to the

252 policing behavior. We were not able to observe direct aggressive interactions between the

253 adult queen and the queen larvae, adult queens are known to attack young unmated queens

254 (Ruel et al. 2013a). They also spray the content of their Dufour gland on adult challengers,

255 which stimulates aggression by workers (Ruel et al. 2013a). A similar behavior was shown in

256 other species (Heinze et al. 1994; Monnin and Ratnieks 2001; van Zweden and d'Ettorre

257 2010; Smith et al. 2012).

258 Both in natural and laboratory conditions, the lack of a queen in a colony of $A$. senilis

259 stimulates the production of a few new queens (Ruel et al. 2013a; Villalta et al. 2015). The 
production of only a few young queens after the queen death is adaptive at the colony level because only one of them is likely to succeed to her mother while the others will be rapidly eliminated by the workers. Therefore, allocating a lot of resources to the production of many queens would counterproductive for a colony. However, this tends to increase competition among bipotent larvae for who will become the next queen. The underlying mechanism is complex and our results do not support the hypothesis according to which queen-destined larvae inhibit the development of younger bipotent larvae into queens. However, they highlight the cost of producing queens with respect to workers: the more $3^{\text {rd }}$ instar larvae were added in the first week of experiment 2, the lower was the proportion of queens among the produced pupae during the following weeks. In addition, there was a strong effect of the source colony on the capacity to rear larvae and to produce new queens. This may result from colony-level behavioral syndromes whereby workers of some colonies are more efficient in nursing larvae than others (Blight et al. 2015).

Several studies have highlighted the role of cuticular HCs in ant communication both within and between colonies. Within colonies, the queen and her eggs arbor specific HCs profiles that differ from workers and worker-laid eggs (Endler et al. 2004; Ruel et al. 2013a; Ruel et al. 2013b). Quiet surprisingly, the larvae possessed very few HCs and no significant qualitative or quantitative difference could be detected. In particular, specific dimethylalkanes that abound on adult queens and on their eggs were completely absent on the larvae. In addition, the total amount of HCs detected on the larvae $(21.7 \pm 1.4 \mathrm{ng}$ vs $12.6 \pm 0.8 \mathrm{ng}$, for queens and workers, respectively) was smaller than on the eggs ( $87 \pm 9 \mathrm{ng}$ vs $73 \pm 13 \mathrm{ng}$ ) which volume is approximately 10 times lower (Ruel et al. 2012). HCs are also involved in nestmate recognition and their very low concentration on larval cuticle is in line with larval "chemical insignificance", that is, the fact that they can easily be exchanged between colonies without being aggressed (Signorotti et al. 2014). This also suggests that workers are able to discriminate between worker and queen larvae using other cues, which may include volatile pheromones, or non chemical signals like the behavior or the morphology. 

In conclusion, the results of this study clearly show that workers of $A$. senilis are able

288 to detect and eliminate larvae that would selfishly develop into queens in small queenright 289 colonies. This phenomenon, which depends on the presence of and contact with the free 290 queen, is similar in many points to the worker policing observed in primitive queenless 291 species. Further studies should intend to identify the signals allowing adult workers to detect 292 and eliminate queen-destined larvae.

293

\section{ACKNOWLEDGEMENTS}

295 We wish to thank Ana Carvajal for helping carry out some of the experiments and Jessica 296 Pearce for her English editing services. Irene Villalta's contract and this project were funded 297 by grant number CGL2012-36181 and CGL2009-12472/BOS (from the Spanish Ministry of 298 Economy and Competitiveness and the FEDER), awarded to Xim Cerdá and Raphaël 299 Boulay. 


\section{REFERENCES}

Beyer WH (1987) CRC Standard Mathematical Tables, 28th ed. CRC Press, Boca Raton, FL.

Blight O, Díaz-Mariblanca GA, Cerdá X, Boulay R (2015). A proactive-reactive syndrome affects group success in an ant species. Behav Ecol: (in press)

Bonavita-Cougourdan A, Passera L (1978). Étude comparative au moyen d'or radio-actif de l'alimentation des larves d'ouvrières et des larves de reine chez la fourmi Plagiolepis pygmaea Latr. Insectes Soc 25: 275-287

Boulay R, Cerda X, Fertin A, Ichinose K, Lenoir A (2009). Brood development into sexual females depends on the presence of a queen but not on temperature in an ant dispersing by colony fission, Aphaenogaster senilis. Ecol Entomol 34: 595-602

Boulay R, Hefetz A, Cerdá X, Devers S, Francke W,Twele R, Lenoir A (2007). Production of sexuals in a fission-performing ant: dual effects of queen pheromones and colony size. Behav Ecol Sociobiol 61: 1531-1541

Bourke AF, Ratnieks FL (1999). Kin conflict over caste determination in social Hymenoptera. Behav Ecol Sociobiol 46: 287-297

Brian M (1973). Caste control through worker attack in the ant Myrmica. Insectes Soc 20: 87102

Caut S, Jowers MJ, Cerda X, Boulay RR (2013). Questioning the mutual benefits of myrmecochory: a stable isotope based experimental approach. Ecol Entomol 38: 390-399

Chapuisat M, Keller L (1999). Extended family structure in the ant Formica paralugubris: the role of the breeding system. Behav Ecol Sociobiol 46: 405-412

Cnaani J, Borst DW, Huang Z-Y,Robinson GE, Hefetz A (1997). Caste determination in Bombus terrestris: differences in development and rates of $\mathrm{JH}$ biosynthesis between queen and worker larvae. J Insect Physiol 43: 373-381

Cronin AL, Molet M, Doums C, Monnin T, Peeters C (2013). Recurrent evolution of dependent colony foundation across eusocial insects. Annu Rev Entomol 58: 37-55 
Cuvillier-Hot V,Cobb M,Malosse C, Peeters C (2001). Sex, age and ovarian activity affect cuticular hydrocarbons in Diacamma ceylonense, a queenless ant. J Insect Physiol 47: $485-493$

Endler A, Liebig J, Schmitt T, Parker JE, Jones GR, Schreier P, Hölldobler B (2004). Surface hydrocarbons of queen eggs regulate worker reproduction in a social insect. Proc Natl Acad Sci USA 101: 2945-2950

Gilley DC (2001). The behavior of honey bees (Apis mellifera ligustica) during queen duels. Ethology 107: 601-622

Heinze J, Holldobler B, Peeters C (1994). Conflict and cooperation in ant societies Naturwissenschaften 81: 489-497. doi 10.1007/s001140050114

Ichinose K, Boulay R, Cerdá X, Lenoir A (2009). Influence of queen and diet on nestmate recognition and cuticular hydrocarbon differentiation in a fission-dispersing ant, Aphaenogaster senilis. Zool Sci 26: 681-685

Ito $F$ (1993). Social organization in a primitive ponerine ant: queenless reproduction, dominance hierarchy and functional polygyny in Amblyopone sp.(reclinata group)(Hymenoptera: Formicidae: Ponerinae). J Nat Hist 27: 1315-1324

Kamakura M (2011). Royalactin induces queen differentiation in honeybees. Nature 473: $478-483$

Kikuta N, Tsuji K (1999). Queen and worker policing in the monogynous and monandrous ant, Diacamma sp. Behav Ecol Sociobiol 46: 180-189

Le Conte Y, Hefetz A (2008). Primer pheromones in social hymenoptera. Annu Rev Entomol 53: $523-542$

Liebig J, Peeters C, Oldham NJ, Markstädter C, Hölldobler B (2000). Are variations in cuticular hydrocarbons of queens and workers a reliable signal of fertility in the ant Harpegnathos saltator? Proc Natl Acad Sci USA 97: 4124-4131

Monnin T, Peeters C (1999). Dominance hierarchy and reproductive conflicts among subordinates in a monogynous queenless ant. Behav Ecol 10: 323-332 
Monnin T, Ratnieks FL (2001). Policing in queenless ponerine ants. Behav Ecol Sociobiol 50: 97-108

Monnin T, Ratnieks FL, Jones GR, Beard R (2002). Pretender punishment induced by chemical signalling in a queenless ant. Nature 419: 61-65

Pamilo P (1991). Evolution of colony characteristics in social insects. I. Sex allocation. Am Nat 137: 83-107

Peeters C, Billen J, Hölldobler B (1992). Alternative dominance mechanisms regulating monogyny in the queenless ant genus Diacamma. Naturwissenschaften 79: 572-573

Peeters C, Higashi S (1989). Reproductive dominance controlled by mutilation in the queenless ant Diacamma australe. Naturwissenschaften 76: 177-180

Penick CA, Liebig J (2012). Regulation of queen development through worker aggression in a predatory ant. Behav Ecol 23: 992-998

R Core Team (2012). R: A language and environment for statistical computing.

Ruel C, Cerdá X, Boulay R (2012). Behaviour-mediated group size effect constrains reproductive decisions in a social insect. Anim Behav 84: 853-860

Ruel C, Hefetz A, Cerdá X, Boulay R (2013a). Recognition of caste and mating status maintains monogyny in the ant Aphaenogaster senilis. Behav Ecol Sociobiol 67: $1295-1305$

Ruel C, Lenoir A, Cerdá X, Boulay R (2013b). Surface lipids of queen-laid eggs do not regulate queen production in a fission-performing ant. Naturwissenschaften 100: 91100

Signorotti L, Jaisson P, d'Ettorre P (2014). Larval memory affects adult nest-mate recognition in the ant Aphaenogaster senilis. Proc R Soc B 281: 20132579

Smith CR, Mutti NS, Jasper WC, Naidu A, Smith CD, Gadau J (2012). Patterns of DNA methylation in development, division of labor and hybridization in an ant with genetic caste determination. PLoS One 7: e42433-e42433

Smith CR, Suarez AV (2010). The trophic ecology of castes in harvester ant colonies. Funct Ecol 24: 122-130 
Smith CR, Toth AL, Suarez AV, Robinson GE (2008). Genetic and genomic analyses of the division of labour in insect societies. Nature Reviews Genetics 9: 735-748

Tay WT, Crozier RH (2000). Nestmate interactions and egg-laying behaviour in the queenless ponerine ant Rhytidoponera sp. 12. Insectes Soc 47: 133-140

van Zweden JS, d'Ettorre P (2010). Nestmate recognition in social insects and the role of 390 hydrocarbons. Insect hydrocarbons: biology, biochemistry and chemical ecology 11: 222-243

392

393

394

395

396

397

398

399

400

401

402

403

404

405

406

407

408

409

410

Vargo EL, Passera L (1991). Pheromonal and behavioral queen control over the production of gynes in the Argentine ant Iridomyrmex humilis (Mayr). Behav Ecol Sociobiol 28: $161-169$

Villalta I, Angulo E, Devers S, Cerdá X, Boulay R (2015). Regulation of worker egg laying by larvae in a fission-performing ant. Anim Behav 106: 149-156

Wenseleers T, Helanterä H, Hart A, Ratnieks FL (2004). Worker reproduction and policing in insect societies: an ESS analysis. J Evol Biol 17: 1035-1047

Wilson EO (1971) The Insect Societies. Harvard, MS.

Wolschin F, Mutti NS, Amdam GV (2011). Insulin receptor substrate influences female caste development in honeybees. Biol Lett 7: 112-115 


\begin{tabular}{llll}
\hline C25 & $0.30 \pm 0.06$ & $0.57 \pm 0.14$ & 0.14 \\
C26 & $0.25 \pm 0.07$ & $0.26 \pm 0.07$ & 0.98 \\
C27 & $1.09 \pm 0.31$ & $1.45 \pm 0.42$ & 0.04 \\
3MeC27 & $0.72 \pm 021$ & $0.88 \pm 0.26$ & 0.71 \\
C28 & $0.12 \pm 0.03$ & $0.02 \pm 0.01$ & 0.02 \\
$10+12 M e C 28$ & $0.17 \pm 0.05$ & $0.20 \pm 0.06$ & 0.86 \\
C29 & $2.09 \pm 0.60$ & $2.54 \pm 0.73$ & 0.18 \\
$11 M e C 29$ & $0.25 \pm 0.07$ & $0.14 \pm 0.04$ & 0.09 \\
$5 M e C 29$ & $0.36 \pm 0.10$ & $0.31 \pm 0.09$ & 0.44 \\
C30 & $0.24 \pm 0.07$ & $0.22 \pm 0.06$ & 1.00 \\
Sum & $5.58 \pm 1.61$ & $6.59 \pm 1.90$ & 0.41 \\
\hline
\end{tabular}

411

412 Table 1: HCs composition of queen- and worker-destined larvae. Compounds are ordered by

413 retention time. Quantities expressed in ng per larva are means \pm SE. The $\alpha$ threshold of 414 significance is 0.005 after the Holm Bonferroni correction.

415

416 
Figure legends:

418

419 Fig. 1: Contacts (a) and aggressions (b) (mean \pm SE) between workers and larvae during the 42030 min observation period in the different resident conditions. Latin and greek letters denote 421 significant differences between worker-destined larvae queen-destined larvae, respectively, across experimental conditions. Stars denote differences between larval castes within resident conditions. Dashed and white histograms represent groups that received queen and worker 3rd instar larvae, respectively.

Fig 2: Survival probability of worker-destined (white bars) and queen-destined (dashed bars) larvae (mean $\pm \mathrm{SE}$ ) after 5 days in four resident conditions. Greek letters denote significant differences across experimental conditions for the queen-destined larvae. Stars denote significant differences between worker and queen destined larvae among resident conditions.

Fig. 3: Total production of pupae (a) and proportion of queens among the diploid pupae (b)

436 that developed from $1^{\text {st }}$ instar larvae as a function of the number of 3rd instar larvae added

437 during the first week of experiment. Black symbols / solid line and white symbols / dotted line 438 represent groups that received queen-destined and worker-destined 3rd instar larvae, 439 respectively. 
Figure 1

a.

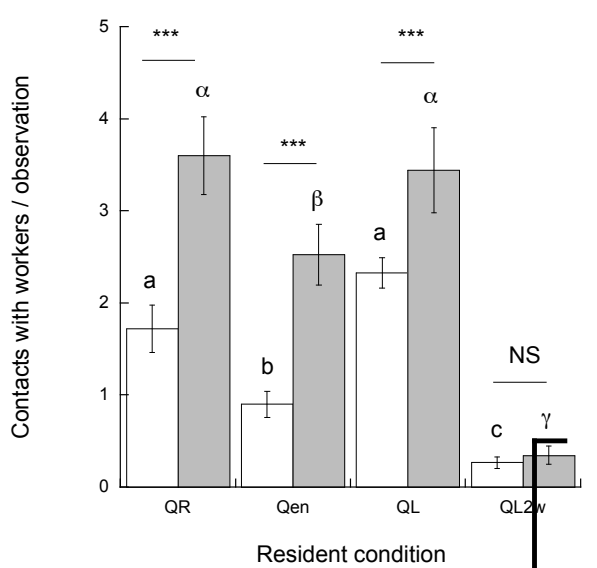

b.

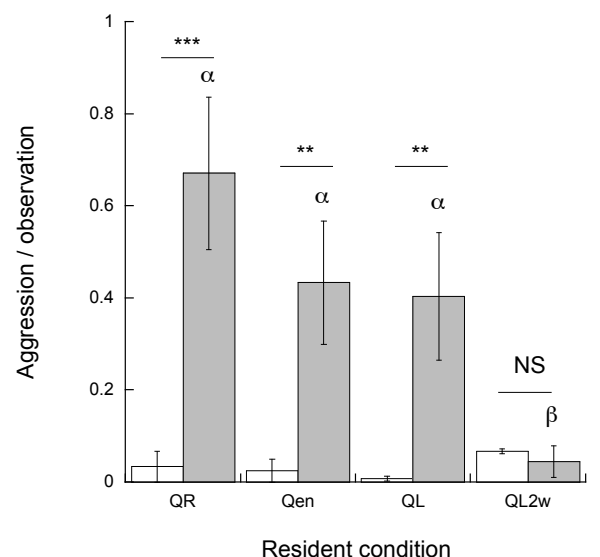


Figure 2

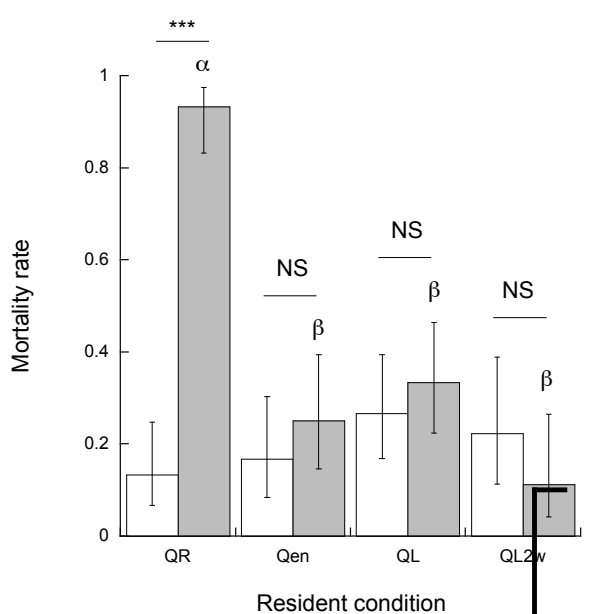

448 
Figure 3

a.

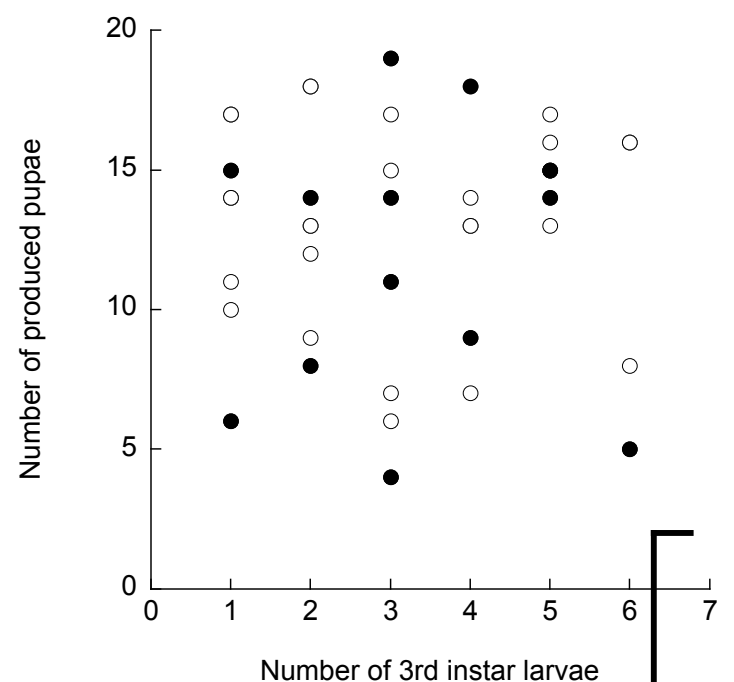

b.

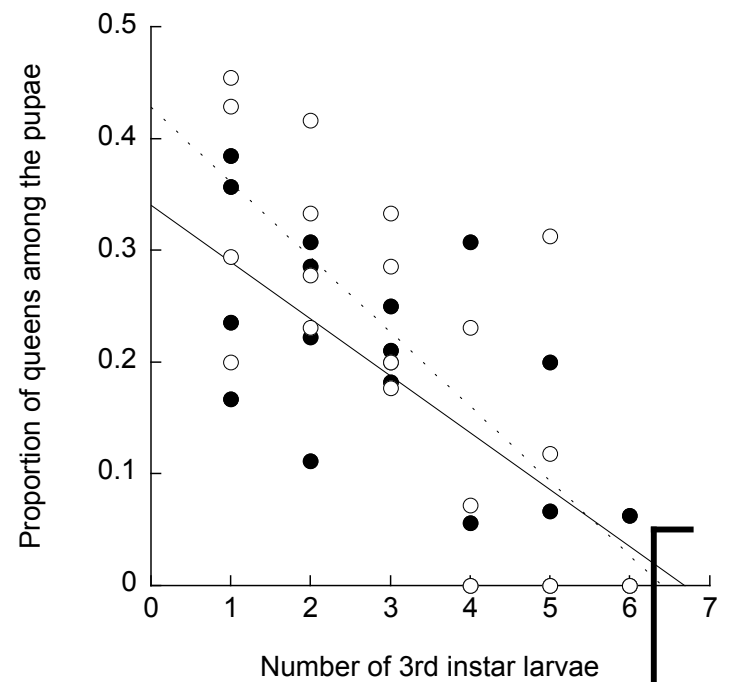

451

452 
453

454

455

456

a.

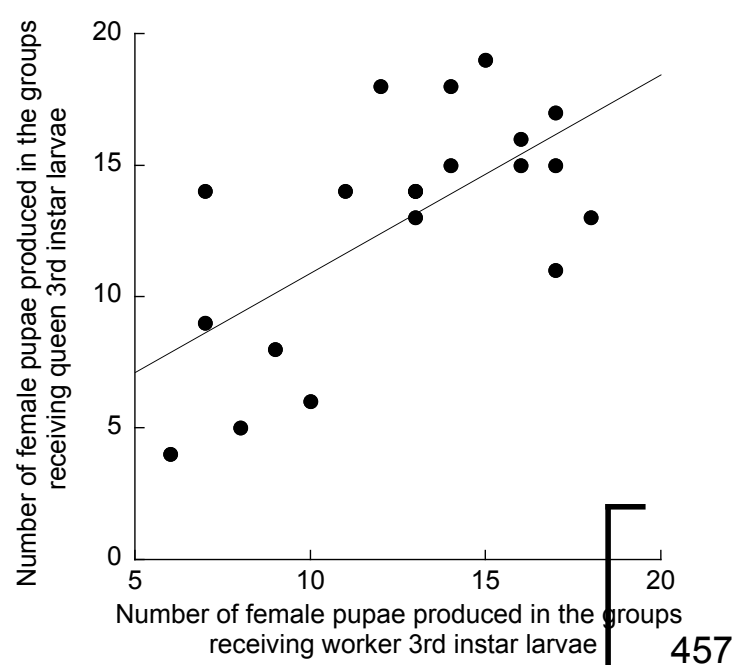

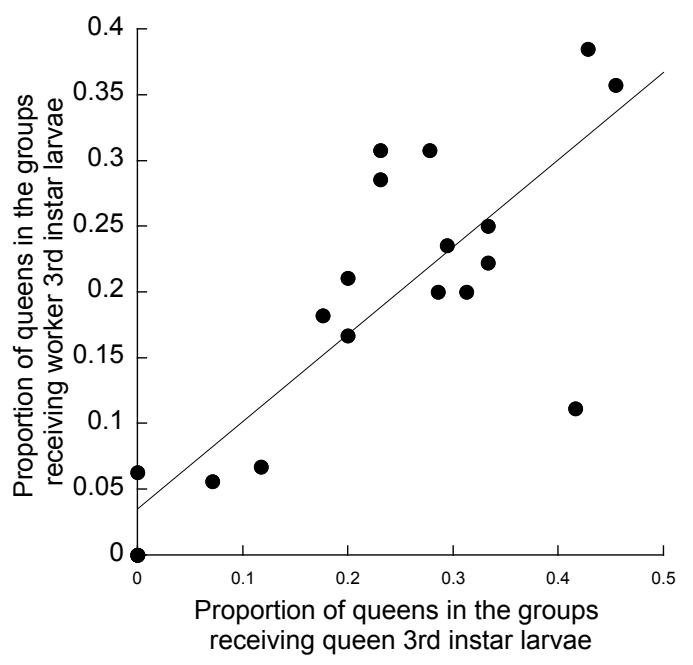

458

459 